\title{
Adding Trauma-Informed Care at a Bereavement Camp to Facilitate Posttraumatic Growth: A Controlled Outcome Study
}

\author{
Irene Searles McClatchey \\ Rachel Frances Raven
}

\begin{abstract}
Background: Studies on posttraumatic growth (PTG) among bereaved youth are rare; outcome studies on how to facilitate PTG among this population are even more scarce. Objectives: This study examined the addition of trauma-informed care to bereavement interventions to foster PTG in youth attending a weekend-long bereavement camp. Method: A total of 105 participants completed standardized measures of posttraumatic growth and posttraumatic stress disorder after which 52 of the participants took part in a camp session. Ninety-five of the participants from both groups were posttested four weeks after the camp session. Results: Multiple Regression showed that PTG scores were significantly greater at posttest for the treatment group. No significant changes in PTSD were found in either group, although the presence of dissociative symptoms decreased significantly among campers in the treatment group. Conclusions: Findings suggest trauma-informed care may increase posttraumatic growth among youth coping with loss. Implications for future studies and clinical practice are discussed.
\end{abstract}

Keywords: Posttraumatic growth; trauma-informed care; childhood bereavement; bereavement camp; posttraumatic stress disorder symptoms

Many children experience the death of a parent. There were 153 million orphans under the age of 18 worldwide in 2009 (United States Agency for International Development [USAID], 2012). Twelve percent of these were double orphans, having lost both parents. In the United States, approximately 1.9 million children under the age of 18 received death benefits from a parent in 2014 (U.S. Social Security Administration [SSA], n.d.). This estimate does not include children with uninsured, unemployed, or undocumented parents, suggesting that the number of children who have experienced the loss of a parent is higher. The loss of a loved one, though traumatic for anyone, can be especially difficult for children and adolescents. Research has shown several short and long-term effects of parental bereavement in children: difficulties in school, developmental delays, higher rates of substance abuse, depression, deviance, increased risk of mortality into early adulthood, and numerous physiological, health, social and psychological issues (Dopp \& Cain, 2012; Ellis, Dowrick, \& Lloyd-Williams, 2013; Li et al., 2014; McClatchey, Vonk, \& Palardy, 2009). However, data have also consistently presented the potential for positive change following a struggle with trauma, also known as posttraumatic growth, or PTG (Kilmer, 2006; Tedeschi \& Calhoun, 1995). This construct helps researchers investigate the transformative effects of distress and has been documented in youth following various traumas: illness, earthquakes, hurricanes, terrorism, and death of a loved one (Arpawong, Oland, Milam, Ruccione, \& Meeske, 2013; Jia, Ying, Zhou, Wu, \& Lin, 2015; Kilmer \& Gil-Rivas, 2010; Laufer \& Solomon, 2006; Lin et al., 2014). With the negative effects on children who have experienced loss, the ability to recognize, and possibly even encourage posttraumatic

Irene S. McClatchey, PhD, LCSW is an Associate Professor and Director of the Master of Social Work Program at Kennesaw State University, Kennesaw, GA 30144. Rachel F. Raven is a medical social worker and discharge planner at Salude Rehab in Suwanee, GA 30024

Copyright () 2017 Authors, Vol. 18 No. 1 (Spring 2017), 349-368, DOI: 10.18060/21239 (cc) BY This work is licensed under a Creative Commons Attribution 4.0 International License. 
growth through trauma-informed care is imperative (Kilmer et al., 2014; Steele \& Kuban, 2011). Nevertheless, despite this stated need, there are few outcome studies examining whether trauma-informed care increases PTG in children. The current study is an attempt to fill this gap in the literature.

\section{Definitions and Distinctions}

PTG, though frequently studied amongst adults, has garnered little attention among children, with no clear standard for measurement in youth and few findings regarding the trajectory of growth (Kilmer et al., 2014; Kilmer et al., 2009). Various studies have examined resilience in children, but researchers have only recently begun scrutinizing the role of trauma-informed care in fostering PTG (Hooper, Marotta, \& Lanthier, 2008; Malchiodi, Steele, \& Kuban, 2008; Steele \& Kuban, 2011). Posttraumatic growth stems from the idea of "cognitive processing," which is the re-examination of beliefs that occurs after an unexpected trauma (Tedeschi, Calhoun, \& Cann, 2007, p. 398). Though similar to resilience, PTG differs in that it denotes positive changes following distress, as opposed to "the ability to manage despite trauma" (Levine, Laufer, Stein, Hamama-Raz, \& Solomon, 2009 , p. 285). Posttraumatic growth does not come from the event itself, but rather "the struggle in the wake of the trauma" (Tedeschi \& Calhoun, 1995, p. 157). This struggle is a result of the traumatic events casting doubt on an individual's pre-trauma perspectives: "shattering their assumptions about the world and forcing a reconfiguration of an individual's goals, beliefs, and...worldview" (Meyerson, Grant, Carter, \& Kilmer, 2011, p. 950).

In the wake of disaster, there are countless adverse effects, but burgeoning literature in the last two decades has identified the many positive changes associated with posttraumatic growth (Kissil, Nino, Jacobs, Davey, \& Tubbs, 2010; Levine et al., 2009; Tedeschi \& Calhoun, 2004). These changes come in many forms, but tend to fall into a few main categories: changed self-perceptions, a different perspective on one's relationships, a changed philosophy of life, and a deepening of one's spiritual and existential being (Calhoun \& Tedeschi, 2006). Changed self-perceptions include an increased sense of survival, strength, and endurance; altered views concerning one's relationships including deeper compassion and empathy, greater appreciation of one's real friends, and an understanding of whom one can rely on; a new worldview as exemplified in modified values and priorities; and proliferation of one's spiritual life providing a broader view of one's existence (Meyerson et al., 2011).

However, not all researchers agree that cognitive change is enough to create personal growth. Hobfoll and colleagues (2007) argue that there also needs to be some evidence of behavioral changes to show real posttraumatic growth. Other researchers see PTG as having an illusory side in addition to growth (Zoellner \& Maercker, 2006).

\section{Posttraumatic Growth and Posttraumatic Stress Disorder}

The Diagnostic Statistical Manual (DSM-5, American Psychological Association [APA], 2013) describes the diagnostic criteria for Posttraumatic Stress Disorder (PTSD) to include having experienced, witnessed, or learned about a traumatic event happening to a 
close friend or family member, or being exposed to "repeated or extreme aversive details of the traumatic event" (p. 271). In addition, symptoms from each of the following clusters need to be present: intrusion, avoidance, negative alterations in cognitions and mood, and alterations in arousal and reactivity. The symptoms have to last more than one month, and cause "clinically significant distress or impairment in social, occupational, or other important areas of functioning" (p.272) not caused by substance abuse or a co-occurring illness.

Posttraumatic stress disorder symptoms have been shown to be significantly associated with PTG in several studies (Devine, Reed-Knight, Loiselle, Fenton, \& Blount, 2010; Hafstad, Kilmer, \& Gil-Rivas, 2011; Jia et al., 2015), with research suggesting that it may play a catalytic role in the posttraumatic growth process among youth (Kilmer \& Gil-Rivas, 2010; Kilmer et al., 2009). Zebrack et al. (2015), in their work with adolescent cancer survivors, found that PTG is not only related to PTSD, but is potentially predicated upon experiencing or re-experiencing some degree of distress. These findings have lead researchers to the two-dimensional stress response perspective (Linley \& Joseph, 2004), which posits that growth and distress, rather than being opposite endpoints on the experiential scale, are instead independent dimensions capable of coexisting within an individual at the same time where "high scores on one dimension do not necessarily imply low scores on the other dimension" (p. 18). Other studies have found no relationship between PTSD and PTG (Glad, Jensen, Holt, \& Ormhaug, 2013; Laufer, Hamama-Raz, Levine, \& Solomon, 2009; Phipps, Long, \& Ogden, 2007).

\section{Posttraumatic Stress Disorder and Grief}

Uncomplicated grief involves feelings of sadness, temporary lack of interest in regular activities, sleep and appetite problems, and inability to focus (Friedman, 2012). Some researchers have found that children generally do well in the grieving process (Brown, Sandler, Tein, Liu, \& Haine, 2007). Other studies show that a fairly large number of children experience PTSD and complicated grief symptoms when losing a parent (McClatchey et al., 2009). In addition, studies have shown that PTSD is present to an equal degree in bereaved children whether the death was expected or sudden and violent (Kaplow, Howell, \& Layne, 2014; McClatchey et al., 2009). Regardless of the number of bereaved children affected by PTSD, for those who are, the PTSD symptoms may interfere with the grief process (Cohen, Mannarino, Greenberg, Padlo, \& Shipley, 2002).

\section{PTG among Youth}

Although there has been a growing body of literature on PTG among youth following various events such as hurricanes (Kilmer \& Gil-Rivas, 2010), natural disasters (Cryder, Kilmer, Tedeschi, \& Calhoun, 2006), earthquakes (Jia, et al., 2015), terrorism (Laufer \& Solomon, 2006), and illness (Arpawong et al., 2013), few studies address posttraumatic growth among bereaved children and adolescents. PTG among bereaved youth may manifest as increased caring for and stronger bonds with loved ones and friends (Oltjenbruns, 1991), gratitude, and an appreciation for life (Brewer \& Sparkes, 2011). Psychological distress and seeking support from adults are predictors of PTG among bereaved youth, but age, gender, ethnicity, time, or seeking support from siblings and peers 
are not (Wolchik, Coxe, Tein, Sandler, \& Ayers, 2009).

Kilmer et al.'s (2014) recent literature review, though not an outcome study, discusses the implications of emerging PTG research and offers ways in which professionals can foster this growth in juveniles. Current evidence has demonstrated the capacity for children and adolescents to experience PTG and has even uncovered some fundamental components of this process. However, as Kilmer et al. (2014) underscore "it is imperative to acknowledge the variability in children's psychological mindedness or self-understanding and awareness" (p. 507). By not just recognizing this adaptability in youth, but catering specifically to it, practitioners can begin to facilitate PTG through trauma-informed care. Using trauma-focused cognitive behavioral therapy (TF-CBT), Judi's House, a nonprofit, community-based grief center, does just that. A ten-week intervention, including individual, family, and group modalities, this program is "designed to help promote emotional regulation and provide psycho-education about trauma and loss, grief reactions and responses, and diverse positive coping strategies" (p. 514). Through the use of TFCBT, peer support, reflection and reframing practices, and carefully paced activities, professionals can expand on the Judi's House model and develop innovative strategies for fostering PTG in youth. Again, there are no outcome studies on the effectiveness of the program.

\section{Outcome Studies}

There are few outcome studies on fostering posttraumatic growth among children, with recent literature only providing a glimpse of the possibilities. One study, completed by Glad and colleagues (2013) examined the prevalence of PTG among 148 Norwegian youth exposed to various traumas. Each child was treated using trauma-focused cognitive behavioral therapy in a mental health clinic and was assessed for both PTSD and PTG at pre- and post-treatment. PTG increased significantly from pre- to post-treatment, with $15 \%$ of participants reporting positive changes at pre-test and 35\% at post-test. However, the study lacked a control group. Also, although there were clinically significant posttraumatic stress reactions displayed among all of the participants, PTSD was not found to have a substantial relationship with levels of PTG. Little, Akin-Little, and Somerville (2011) studied the efficacy of Project Fleur-de-lis, a program designed to help children in the aftermath of Hurricane Katrina. The project used a three-tier method, moving from least intensive to most intensive intervention: Classroom-Camp-Community-Culture Based Intervention (CBI), Trauma-Focused Cognitive Behavior Therapy (TF-CBT), and Cognitive Behavioral Intervention for Trauma in Schools (CBITS). PTG, PTSD, psychosocial functioning, and depression were all assessed throughout the program. Marked improvements were made in all areas and on every tier, except for TF-CBT, which did not have a significant effect on levels of depression. However, the sample was small and there was no control group.

Supporting PTG among bereaved children is an even less explored topic, with only a few researchers addressing this subject. Wolchik and colleagues (2009) discussed an analysis of 50 adolescents and young adults who participated in a sub-study of a larger exploration. The respondents, aged 14 through 22, were randomly assigned to either a preventative group program for youth and caregivers or to a self-study program. Six years 
after entering the study, participants completed the Posttraumatic Growth Inventory (Tedeschi \& Calhoun, 1996). Participation in the Family Bereavement Program, meant to enhance coping and the caregiver-child relationship, did not increase posttraumatic growth levels. Both the small sample size and the fact that the intervention did not specifically address PTG were offered as potential reasons for this outcome. To better promote PTG among youth, the researchers recommend offering a therapeutic environment in which children who have experienced trauma can come together to share and discuss positive changes (Wolchik et al., 2009).

Lin et al. (2014) studied 124 children orphaned by AIDS in Central China. Though PTG is not specifically mentioned, several themes of posttraumatic growth were addressed in the study. Research participants were divided into an intervention group, which included six weekly sessions based on grief theory, and a control group. Results demonstrated that children in the intervention group scored significantly higher than those in the control group in grief processing (thinking about the deceased, searching for meaning, having positive memories, talking and expressing feelings about the deceased), future expectations, hopefulness, and control, and significantly lower in trauma symptoms. However, trauma-informed care was not part of the intervention.

In summary, few studies look at bereaved children and PTG. Of those that exist, the treatment of one did not address PTG specifically (Wolchik et al., 2009) and one did not measure PTG although it did measure cognitive growth (Lin et al., 2014). The current lack of controlled research on effective ways to facilitate PTG among bereaved youth leads to the question: can adding trauma-informed care to grief interventions facilitate PTG among bereaved youth as suggested by some (Kilmer et al., 2014; Steele \& Cuban, 2011)? The current study, based on a subset of data from a larger study, describes, as far as the researchers know, the first controlled outcome study on fostering PTG in bereaved youth with a camp intervention that included trauma-informed care.

\section{Method}

\section{Participants}

Participants for this study were campers at a weekend-long healing camp for bereaved children and adolescents ages 6 through 17. This purposive sample was selected to examine the effect of adding trauma-informed care among bereaved youth in this non-equivalent comparison group study. Bereaved youth were recruited for two separate camp sessions through the school system by a general announcement to school counselors three months before the first camp session and four months before the second camp session. After having registered their children for camp, the parents/guardians were informed of the research project via phone calls and email. A total of 67 campers signed up for the first camp session. The parents/guardians of 52 of the 67 participating campers ( 78 percent) agreed for their children to participate in the study. A total of 69 campers signed up for the second camp session, and parents/guardians of 54 of these campers (78 percent) agreed to allow their children to participate. All children whose parents allowed them to participate assented to do so except for one child in the second camp session. Thus, a total of 105 campers were available for pre-testing. One month later 91 of the campers from the two sessions $(87 \%$ 
response rate) were available for post-testing (see Figure 1).

The 105 campers who completed the pre-test were mostly males (63\%); 53\% were Caucasians; 39\% African Americans, 4\% Latino, and another 4\% Indian and Pacific Islander. Forty-seven percent of the campers had lost a mother, $35 \%$ a father, $13 \%$ a sibling, and 5\% a guardian or grandparent. The campers' age ranged from 6 to $17(M=10.72$; $S D=2.85$ ). The majority of the children and adolescents had experienced a sudden loss (70\%). Sudden or unexpected causes of death included aneurysm, homicide, heart attack, accidental drug overdose, suicide, stroke, car and motorcycle accidents, SIDS, pneumonia, drowning, and asthma. Expected causes of death included cancer, liver failure, end stage heart or kidney disease, chronic heart failure, chronic obstructive pulmonary disease, and alcoholism. Time since death ranged from one month to 57 months $(S D=11.30)$ (see Tables 1 and 2).

Figure 1. Flow of Participants for the Study's Procedures, Assignment, Follow-Up, and Analysis.

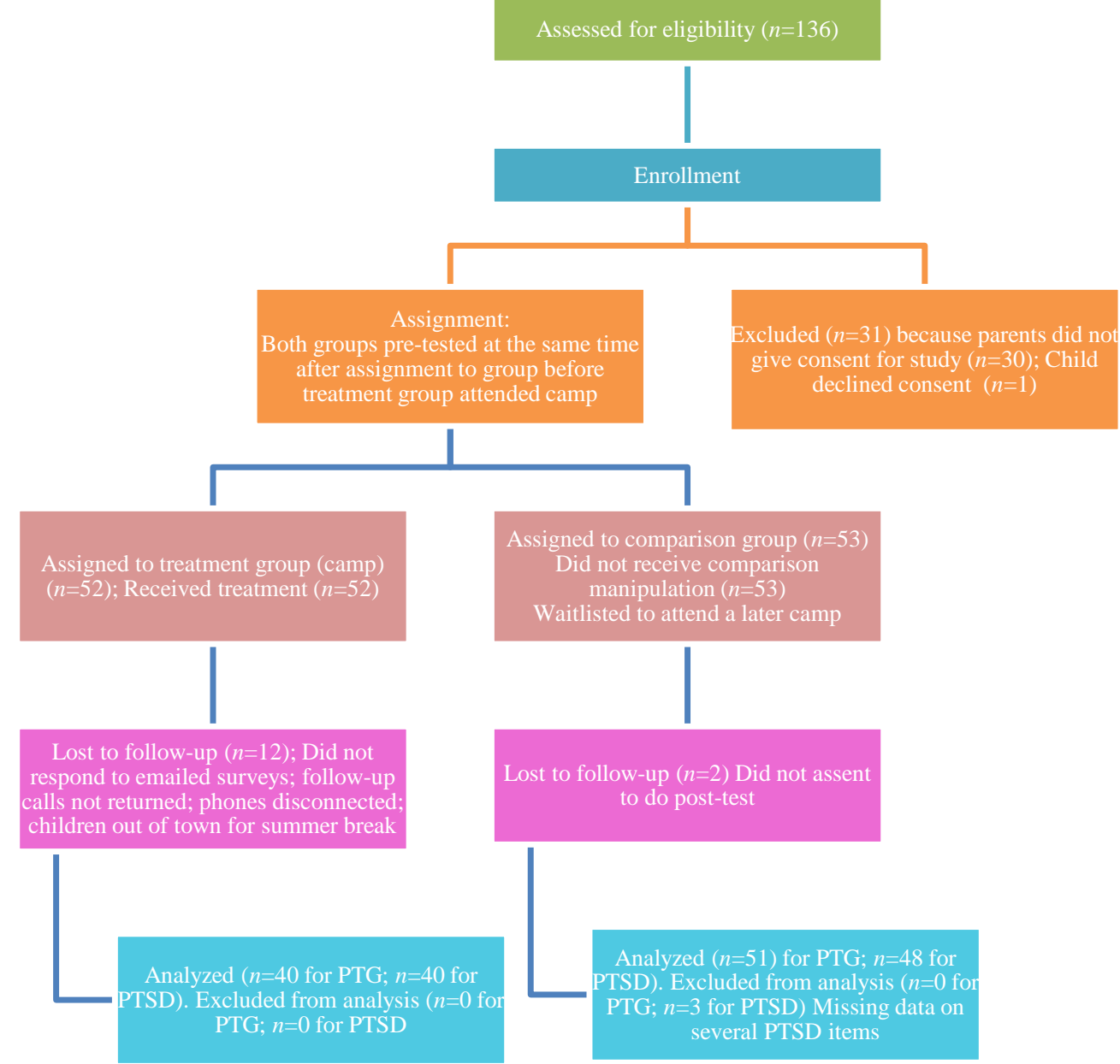

Notes. PTG=Posttraumatic Growth; PTSD=Posttraumatic Stress Disorder; Follow-Up: Both groups post-tested at same time four weeks after treatment group attended camp 
Table 1. Gender, Race, Ages, Type of Loss, Type of Death, and PTSD Dissociative Subtype for Treatment and Comparison Groups

\begin{tabular}{|c|c|c|c|c|c|c|c|}
\hline \multirow[b]{2}{*}{ Demographics } & \multicolumn{2}{|c|}{$\begin{array}{c}\text { Treatment } \\
\text { Group }\end{array}$} & \multicolumn{2}{|c|}{$\begin{array}{c}\text { Comparison } \\
\text { Group }\end{array}$} & \multirow[b]{2}{*}{$\chi^{2}$} & \multirow[b]{2}{*}{$\mathrm{df}$} & \multirow[b]{2}{*}{$p$ Value } \\
\hline & $n$ & $\%$ & $n$ & $\%$ & & & \\
\hline \multicolumn{8}{|l|}{ Gender } \\
\hline Female & 21 & 40 & 18 & 34 & \multirow[t]{2}{*}{0.46} & \multirow[t]{2}{*}{1} & \multirow[t]{2}{*}{.50} \\
\hline Male & 31 & 60 & 35 & 66 & & & \\
\hline \multicolumn{8}{|l|}{ Ethnicity } \\
\hline Caucasian & 34 & 65 & 22 & 42 & \multirow[t]{5}{*}{6.01} & \multirow[t]{5}{*}{1} & \multirow[t]{5}{*}{.02} \\
\hline African America & 15 & 29 & 26 & 49 & & & \\
\hline Hispanic & 3 & 6 & 1 & 2 & & & \\
\hline Indian & & & 3 & 5 & & & \\
\hline Pacific Islander & & & 1 & 2 & & & \\
\hline Age Groups [Mean (SD)] & \multicolumn{2}{|c|}{$10.73(2.72)$} & 10.72 & 00) & \multirow{4}{*}{.08} & \multirow{4}{*}{1} & \multirow{4}{*}{.78} \\
\hline $6-11$ & 32 & 62 & 34 & 64 & & & \\
\hline $12-17$ & 20 & 38 & 19 & 36 & & & \\
\hline Range & $6-17$ & & $6-16$ & & & & \\
\hline \multicolumn{8}{|l|}{ Type of Loss } \\
\hline Mother & 18 & 35 & 31 & 58 & & & \\
\hline Father & 20 & 38 & 17 & 32 & & & \\
\hline Sibling & 12 & 23 & 2 & 4 & & & \\
\hline G Gparent & 2 & 4 & 3 & 6 & & & \\
\hline \multicolumn{8}{|l|}{ Type of Death } \\
\hline Sudden/violent & 37 & 71 & 36 & 68 & \multirow[t]{2}{*}{.13} & \multirow[t]{2}{*}{1} & \multirow[t]{2}{*}{.72} \\
\hline Expected & 15 & 29 & 17 & 32 & & & \\
\hline \multicolumn{8}{|l|}{ PTSD Dissociative Subtype } \\
\hline Yes & 29 & 56 & 28 & 58 & & & \\
\hline No & 23 & 44 & 20 & 42 & .07 & 1 & .80 \\
\hline
\end{tabular}

Notes. G Gparent = Guardian Grandparent; PTSD = Post-traumatic Stress Disorder.

Table 2. Independent Sample t-Tests of Mean Differences in Time Since Loss, PTG and PTSD Index Scores for Treatment and Comparison Groups

\begin{tabular}{|c|c|c|c|c|c|c|c|c|c|}
\hline \multirow[b]{2}{*}{ Measure } & \multicolumn{3}{|c|}{ Treatment Group } & \multicolumn{3}{|c|}{ Comparison Group } & \multirow[b]{2}{*}{$t$} & \multirow[b]{2}{*}{$d f$} & \multirow[b]{2}{*}{$p$ Value } \\
\hline & $M$ & $S D$ & $n$ & $M$ & $S D$ & $n$ & & & \\
\hline Months & 12.25 & 11.07 & 52 & 9.75 & 11.50 & 53 & 1.13 & 103 & .26 \\
\hline Range & $1-48$ & & & $1-57$ & & & & & \\
\hline PTG scores & 30.40 & 6.46 & 52 & 27.21 & 7.08 & 52 & 2.33 & 102 & $.02^{*}$ \\
\hline Ranges & $13-40$ & & & $10-40$ & & & & & \\
\hline PTSD Scores & 24.85 & 17.64 & 52 & 26.75 & 19.45 & 48 & -.51 & 98 & .61 \\
\hline Range & $1-71$ & & & $0-84$ & & & & & \\
\hline
\end{tabular}

\section{Measurements}

Posttraumatic Growth. The researchers used the Revised Posttraumatic Growth Inventory for Children (PTGI-C-R) (Kilmer et al., 2009) to measure posttraumatic growth. This inventory is a 10-item self-report measurement revised from Cryder et al.'s (2006) 
Posttraumatic Growth Inventory for Children (PTGI-C). The PTGI-C-R assesses five PTG domains, including new possibilities, relating to others, personal strength, appreciation of life, and spiritual change using a 4-point scale with 1 representing "no change" and 4 representing "a lot." Questions posed in the different domains include "I now have a chance to do some things I couldn't do before," "I feel closer to other people (friends or family) than I used to," "I can now handle big problems better than I used to," "I appreciate (enjoy) each day more than I used to," and "I understand how God works better than I used to." The Cronbach's alpha for the PTGI-C-R in Kilmer et al.'s study (2009) ranged between 0.77 and 0.81 . For the current study Cronbach's alpha was 0.83 at pretesting, and .89 at post-testing.

Posttraumatic Stress Disorder Symptoms. To measure posttraumatic stress disorder symptoms, the researchers used the fifth section of the University of California at Los Angeles (UCLA) PTSD Reaction Index for DSM-5 (Pynoos \& Steinberg, 2014). This is a 27-item self-report measure of thoughts, feelings, and behaviors that represent posttraumatic stress disorder symptoms linked to the DSM-5 (APA, 2013). The respondents rate items as they pertain to the past month, such as "I am on the lookout for danger or things that I am afraid of (like looking over my shoulder even when nothing is there)", "I have trouble concentrating or paying attention", "I have thoughts like, "The world is really dangerous", and "I have trouble going to sleep, wake up often, or have trouble getting back to sleep," as none, little, some, much, or most. In addition, the scale contains 4 items to assess dissociative subtype, such as, "I feel like things around me are not real, like I am in a dream." Psychometric properties of the UCLA PTSD Reaction Index for DSM-5 are not available but studies are currently being conducted (A. Steinberg, personal communication, December 29, 2015). The UCLA PTSD Index for DSM-5 is created similarly to the UCLA PTSD Reaction Index for DSM IV (Steinberg \& Brymer, 2008). The UCLA PTSD Reaction Index for DSM IV includes three PTSD symptom clusters (re-experiencing, avoidance, and arousal) whereas the UCLA PTSD Reaction Index for DSM-5, in accordance with the DSM-5, includes a fourth cluster - negative alterations in cognitions and mood (APA, 2013; Pynoos \& Steinberg, 2014). When scoring the scale, a score of 3 or 4 indicates that the symptom is present except for items 4,10 , and 26 where a score of 2 or higher indicates presence of the symptom. One or more dissociative symptoms indicate dissociative subtype. In the current study Cronbach's alpha was .90 at pre-testing and .92 at post-testing.

\section{Procedures}

After the local university's Institutional Review Board gave approval for the study, the parents/guardians of campers, who had been recruited through the school system, were informed of the study by a phone call followed by an email to those who indicated interest in the study. The researchers attached a consent form to the email asking for the parents'/guardians' permission for their children to participate in the study. The parents/guardians of the first camp session (Camp A) who agreed for their children to participate (treatment group) brought signed consent forms to the camp when arriving to drop their children off for the weekend camp. Graduate social work students, who had been trained in research procedures and the test instruments, asked the campers who had parental 
consent if they would assent to take part in the study. The graduate students found private spots to administer the instruments to those who assented. The campers then participated in the weekend long camp.

Meanwhile, campers who had signed up for the second camp session (Camp B), to take place four weeks after Camp A, served as the comparison group. The parents of the children in the comparison group had been asked to mail signed consent forms to the researchers in pre-stamped self-addressed envelopes. Graduate social work students contacted these campers the week preceding Camp A via email with an attached assent form. If the youth assented to participate in the study, they were directed to a Qualtrics link (a software tool for the university's researchers to use for on-line surveys) and were asked to assent once more on the site. They then completed the instruments using Qualtrics.

Four weeks after Camp A the campers in the comparison group arrived to Camp B. Upon their arrival, the graduate social work students administered the second testingbefore the campers started participation in camp. In the week leading up to Camp B, the campers from Camp A were emailed a link to the instruments on Qualtrics and were asked to complete the second testing. Thus, the campers attending Camp A (treatment group) were pre-tested right before Camp A and post-tested four weeks later during the week immediately prior to Camp B. The comparison group was pre-tested during the week prior to Camp A and post-tested right before Camp B four weeks later as they arrived to camp but prior to participating in camp (see Figure 1).Therefore, the comparison group did participate in camp, but only after the study was concluded.

\section{The Intervention}

The intervention, developed by a social worker, consisted of a therapeutic weekend stay at a camp. The participants arrived on a Friday afternoon and stayed until Sunday afternoon. During the weekend, they participated in several recreational camp related activities such as a ropes course, canoeing, rock climbing, archery, etc. They also took part in grief-related activities such as poetry writing, journaling, arts performances, a balloon release, and a memorial service. In addition, the campers were divided into groups of six to eight campers according to age and developmental levels to receive six counseling sessions based on trauma-focused grief interventions. The camp follows the four assumptions and six principles of trauma-informed care as described by the Substance Abuse Mental Health Services Administration (SAMHSA, 2015). The four assumptions include basic realization of trauma and its affect; ability to recognize the signs of trauma; a response to trauma; and a pursuit to resist re-traumatization. The six principles stress safety, trustworthiness and transparency, peer support, collaboration and mutuality, empowerment, and awareness of cultural, historical, and gender issues. This approach is a philosophy that guides the camp agency in all of its aspects and for all its shareholders, such as campers, camper families, staff, volunteers, and funders. It is thus far more than a particular intervention. The counselors and co-counselors, the majority of whom were professional social workers and Master of Social Work students, received extensive training in the approach and were provided with a scripted manual that integrates best practices in trauma intervention. These techniques included psycho-education, feeling identification, exposure, stress inoculation techniques, mindfulness, and cognitive 
behavioral therapy. The intervention was based on work by Cohen and Mannarino (2004) and Pynoos, Steinberg, and Wraith (1995).

\section{Analysis and Results}

\section{The Treatment and Comparison Groups}

The researchers first examined the treatment and comparison groups to see if they were comparable. Chi-square analyses revealed that the groups were similar in regards to demographic variables such as gender, age group (6-11; 12-17), type of loss (mother, father), and type of death (expected, unexpected). However, the two groups were different in regards to ethnicities, such that the treatment group had fewer Black participants than the comparison group, $\chi^{2}(1)=6.01, p=.02$. Independent samples $t$-test showed that the two groups were similar regarding time since loss and mean PTSD scores at pretest. The treatment group had higher PTG scores at pretest, $t(102)=2.33, p=0.02$. The campers who dropped out of the study at post-test were not different from those who remained in the study in regards to age group, gender, ethnicity, loss, mode of loss, time since loss, PTG and PTSD pre-test scores.

\section{PTG and PTSD Scores After Camp}

To examine whether PTG scores were different after the trauma-informed camp-based intervention, the researchers used a regression model to look for differences in total PTG scores between participants in the two camps at post-test controlling for total PTG scores at pre-test. Several extraneous variables were added to the model to look for possible predictors of PTG but also to control for differences across the two camps. These variables included age groups $(6-11,12-17)$, ethnicity (White versus non-White), gender, time, type of loss (parental versus non-parental), and mode of loss (sudden/violent versus expected). The children who attended camp had statistically significantly higher PTG scores than the children in the comparison group at post-test $\left(\beta_{\mathrm{TX}}=-2.598 ; p=0.04\right)$. None of the covariates entered were significantly linked to PTG scores (see Table 3). In addition, in a separate regression model, there was no relationship detected between PTSD and PTG scores $(p=.63)$.

Table 3. Regression Coefficients Model Results for Posttraumatic Growth Outcome

\begin{tabular}{|c|c|c|c|c|c|}
\hline \multirow[b]{2}{*}{ Variable } & \multicolumn{2}{|c|}{$\begin{array}{l}\text { Posttraumatic Growth } \\
\text { Outcome }(n=91)\end{array}$} & \multirow[b]{2}{*}{$p$ Value } & \multirow[b]{2}{*}{$F$} & \multirow[b]{2}{*}{$R^{2}$} \\
\hline & $B$ & $S E$ & & & \\
\hline Camp & -2.60 & 1.27 & $0.04^{*}$ & 7.55 & 0.42 \\
\hline Age-group & -1.67 & 1.26 & 0.19 & & \\
\hline Ethnicity & -0.95 & 1.28 & 0.46 & & \\
\hline Gender & 0.26 & 1.29 & 0.84 & & \\
\hline Time & 0.06 & 0.06 & 0.33 & & \\
\hline $\operatorname{Loss}^{\mathrm{a}}$ & -1.26 & 1.57 & 0.43 & & \\
\hline Mode of Loss ${ }^{b}$ & -0.78 & 1.28 & 0.54 & & \\
\hline PTG Pretest Scores & .53 & .09 & $<0.001$ & & \\
\hline
\end{tabular}


A similar regression model was used to examine the level of PTSD symptoms after camp. Total PTSD scores at post-test were entered as the dependent variable and camp was entered as the independent variable. Total PTSD scores at pre-test were entered as a covariate. The same extraneous variables entered in the first regression model, such as age group, ethnicity, gender, time, type of loss, and mode of loss, were also included in the model. The children who attended camp had lower total PTSD scores than the children in the comparison group. However, the difference was not statistically significant $\left(\beta_{\mathrm{Tx}}=3.31\right.$; $p=.34)$. None of the covariates were significant predictors of PTSD scores.

Furthermore, the researchers studied if participating in the camp decreased the possibility that the children would continue to experience dissociative symptoms. At the post-test, 14 campers $(35 \%)$ in the treatment group experienced dissociative symptoms compared to $29(56 \%)$ at the pre-test. In the comparison group, 32 campers (67\%) experienced dissociative symptoms at post-test as compared to $28(58 \%)$ at the pre-test. Chi-square showed that this difference between the two groups at the post-test was statistically significant with children not attending camp having higher odds of continuing to experience dissociative symptoms than those children who did attend camp, $\chi^{2}(1)=8.77$, $p<.01$.

To investigate whether there were any differences in outcome among various demographic groups, a series of paired $t$-tests (PTGPostTotal-PTGPreTotal and PTSDPostTotal-PTSDPreTotal) were conducted on the treatment and comparison groups. The results indicated that there was a statistically significant increase in PTG in the treatment group for Caucasian children, $t(24)=3.30, p<0.01$, but not for non-White campers; for those who had lost a father, $t(14)=3.26, p=0.01$, and among those participants who had lost a family member to sudden/unexpected loss, $t(27)=3.11, p<0.01$ (see Table 4). There was also a statistically significant decrease in PTSD symptoms among males in the treatment group, $t(22), p<0.04$. None of these statistical changes were detected in the comparison group.

Table 4. Paired Samples t-Test Posttraumatic Growth: Treatment Group

\begin{tabular}{|c|c|c|c|c|c|c|c|c|c|}
\hline & \multirow[b]{2}{*}{$\mathrm{n}$} & \multirow[b]{2}{*}{ Mean } & \multirow[b]{2}{*}{$\mathrm{SD}$} & \multicolumn{2}{|c|}{$\begin{array}{c}\text { Paired Differences } \\
\text { 95\% Confidence } \\
\text { Level }\end{array}$} & \multirow[b]{2}{*}{$\mathrm{df}$} & \multirow[b]{2}{*}{$\mathrm{t}$} & \multirow[b]{2}{*}{$p$ Value } & \multirow[b]{2}{*}{ Power } \\
\hline & & & & Lower & Upper & & & & \\
\hline \multicolumn{10}{|l|}{ PTG } \\
\hline Overall & 40 & 2.60 & 4.58 & 1.13 & 4.07 & 39 & 3.59 & $0.001^{*}$ & 0.95 \\
\hline Whites & 25 & 3.28 & 4.97 & 1.23 & 5.33 & 24 & 3.30 & $0.003^{*}$ & 0.91 \\
\hline Non-whites & 15 & -1.47 & 3.74 & -3.54 & 0.60 & 14 & -1.52 & 0.15 & 0.24 \\
\hline Females & 16 & 3.13 & 4.12 & 0.85 & 5.42 & 15 & 2.94 & $0.01^{*}$ & 0.84 \\
\hline Males & 25 & 2.28 & 4.89 & 0.26 & 4.30 & 24 & 2.33 & $0.03^{* *}$ & 0.65 \\
\hline Father loss & 15 & 4.40 & 5.22 & 1.51 & 7.29 & 14 & 3.26 & $0.01^{*}$ & 0.90 \\
\hline Mother loss & 12 & -0.83 & 4.42 & -3.65 & 1.98 & 11 & -0.65 & 0.53 & 0.11 \\
\hline Sibling loss & 11 & -1.45 & 3.11 & -3.54 & 0.63 & 10 & -1.55 & 0.15 & 0.30 \\
\hline Sudden loss & 28 & 2.86 & 4.87 & 0.97 & 4.74 & 27 & 3.11 & $0.04^{*}$ & 0.87 \\
\hline Expected loss & 12 & -2.00 & 3.98 & -4.53 & 0.53 & 11 & -1.74 & 0.11 & 0.38 \\
\hline
\end{tabular}

*Significant at $\alpha \leq .01$. **Significant at $\alpha<.05$. 
To examine whether camp had a different outcome for those campers who had experienced a sudden/violent loss versus those who had experienced an expected loss, a regression model using post-PTG scores as the dependent variable and camp, pre-PTG scores, type of death, and the interaction between camp and type of death as independent variables. The camp-type of death coefficient was not significant $(p=.815)$. Thus, camp had the same effect on the PTG scores for the two types of death.

\section{Discussion}

In this study, the researchers examined the effects of a bereavement camp using trauma-informed care on posttraumatic growth and posttraumatic stress disorder symptoms among bereaved youth. To the authors' knowledge, this is the first controlled outcome study of a program for bereaved youth applying trauma-informed care to examine its effects on PTG levels. The findings showed statistically higher levels of posttraumatic growth among youth participating in camp as compared to those who did not take part in camp. The results coincide with previous findings in pre-experimental studies examining PTG among youth that had experienced trauma (Glad et al., 2013; Little et al., 2011). PTSD symptoms decreased, but not to a statistically significant degree. However, the number of campers attending the treatment camp experiencing dissociative symptoms was statistically significantly lower after attending camp compared to the number of campers in the comparison group.

In addition, the study showed that the effects of camp on PTG were statistically significant among White youth but not among non-White youth. It may be that the lack of diversity in counselor composition at camp did not allow for the same bonding between African American campers and counselors as for Caucasian participants. Schafer (2007) found that similarities, such as ethnicity, between the counselor and camper are important to a positive camp experience. It is also possible that different ethnicities react differently to trauma and this warrants more exploration.

The change in PTG was also statistically significant among those campers who had lost a father but not for those who had lost a mother. For many of the families attending this camp, the deceased fathers were the primary providers. A new financial situation may have created extra struggles for those who lost a father. However, coming to camp and meeting others with similar struggles, may have given them a sense of increased strength and endurance (Wolchik et al., 2009).

In the current study, campers who had experienced a sudden loss also experienced a statistically significant increase in PTG levels but this was not the case for those campers who had experienced an expected loss. Losing a parent suddenly and/or in a violent manner may create struggles for bereaved children and families, such as ruminations and feelings that the death could have been prevented (Currier, Holland, \& Neimeyer, 2006). This may in turn create feelings of guilt (Nader, 2001). Such feelings of guilt are highlighted at camp in the cognitive behavioral therapy (CBT) group counseling sessions. The use of CBT may help those with sudden loss to be able to let go of their guilt and create the noted posttraumatic growth in the group of campers who experienced a sudden loss. 
Posttraumatic stress disorder symptoms declined to a statistically significant level among males in the treatment group but not among females. Males oftentimes have a more difficult time than females to express emotions (Chaplin \& Aldao, 2013). At camp, males are together with other children and teens their own age, who have had similar traumatic experiences. Such peer support may facilitate processing, an important part of treatment for PTSD, and may have decreased their PTSD symptoms.

\section{Limitations}

Although the treatment intervention described in this study is cost-effective, convenient for participants' families, and demonstrates positive findings, there are some limitations that need to be considered when interpreting the results. First, despite the fact that the quasi-experimental design controls for most threats to internal validity (Campbell \& Stanley, 1963), there are some concerns including the Hawthorne effect and the Placebo effect. The Hawthorne effect, also known as the observer effect, occurs when participants alter their responses or behaviors simply because they are being observed (McCambridge, Witton, \& Elbourne, 2014). It is possible that the campers knew why they were being observed and responded in kind. The placebo effect occurs when participants describe themselves as feeling better because of beliefs about the treatment (Rogers, 2014). The campers knew they were at a healing camp for bereaved youth and may have had preconceived expectations about the treatment rather than have experienced actual changes.

Further limitations include a lack of randomization, limited diversity among the participants, and a shortage of information pertaining to possible intervening variables. While the study did involve a comparison group, due to cost factors and various ethical concerns, the researchers could not incorporate a randomized control group. The treatment and comparison groups were different on two variables - ethnicity and PTG pretest scores. A selection-history threat is a possibility, i.e., some event other than the treatment took place that the treatment group reacted to, but not the comparison group (Trochim, 2006). Regression to the mean also needs to be considered. In addition, it is possible that if the treatment group had included a more diverse ethnic group, the results would have been different. Furthermore, since the children and adolescents referred to the camp may be those who are struggling with their loss as opposed to children who are ostensibly coping well, the results of the study cannot be generalized to all bereaved youth. Moreover, some intervening variables, such as level of relationship intimacy with the deceased and/or surviving parent/guardian or social supports, remain unknown. The subgroups examined were small and the statistical power insufficient to identify small differences between groups. Finally, no method for family-wise error was used. Therefore, care needs to be taken when drawing conclusions in regards to the effectiveness of camp.

Even if camp did influence posttraumatic growth, it is not known if this was due to the addition of trauma-informed care, or whether it was due to other aspects of camp. It may be that just sharing similar experiences with other campers in a therapeutic environment, as suggested by Kilmer et al. (2014), created the positive change. Additionally, having several social work students administering the instruments leaves questions about interrater reliability. It is also unknown what participants' prior treatment experiences were. 
Finally, the authors of the UCLA PTSD Reaction Index for DSM-5 (Pynoos \& Steinberg, 2014) have not shared the instrument's psychometric properties, making the measure's convergent validity with PTSD symptoms unknown. In spite of and because of these limitations, there are significant implications for future research and practice.

\section{Implications for Future Research and Practice}

The findings of this research showed that those campers who had lost a father experienced PTG to a stronger degree than those who had lost a mother. This may be due to financial struggles. It would behoove researchers to include income or socioeconomic status (SES) in future studies to see if it has an impact on PTG. White campers in this study showed more growth in PTG than non-White campers. The possible impact of counselorcamper ethnicity on the outcome of PTG deserves examination. There are also other variables that were not addressed in this study. Social support plays an important role in grief resolution among children (Sveen, Eilegard, Steineck, \& Kreicbergs, 2014), but current studies on its impact on PTG are inconclusive (Kilmer \& Gil-Rivas, 2010; Yu et al., 2010). Future research may want to explore how social supports impact posttraumatic growth. Furthermore, studies with more ethnically diverse participants are needed to examine the relationship between ethnicity and PTG. It would also be important to follow up with campers some time after camp to ascertain whether gains are enduring or temporary. Finally, since there was no relationship between PTSD symptoms and PTG, is trauma necessary for growth after a death? Or is Horowitz (2010) correct in claiming that any successfully completed grief creates growth? One could argue that any bereavement creates a struggle of sorts, even if the death was not traumatic. As Meyerson et al. (2011) state, the event is "shattering their assumptions about the world and forcing a reconfiguration of an individual's goals, beliefs, and...worldview" (p. 950). It is the struggle that creates PTG (Tedeschi \& Calhoun, 1995). Is trauma-informed care and trauma interventions necessary to create this growth? In this study, PTSD symptoms did not decrease significantly, except among males; however, the possibility that the children would continue to experience dissociative symptoms did decrease significantly. In addition, children who had experienced a sudden death had a significant increase in PTG. These findings, and Kirwin and Hamrin's (2005) claim that death of a parent is traumatic for any child, would support the use of trauma-informed care. However, more research is needed to examine the relationship between PTSD symptoms, PTG, and grief.

The results from this study indicate that adding trauma-informed care can be a beneficial approach to guiding children and adolescents through grief and can be done is various settings such as in individual counseling sessions and group settings in schools, hospitals, and hospices. The camp setting used in this study is a convenient setting for most families, who bring their children to the camp setting for one weekend. More agencies that provide services to bereaved youth may want to explore the possibility of establishing weekend camps for their clients. The results also suggest the importance of having counselors from various ethnicities, who are culturally competent to adequately serve all bereaved children and adolescents. Finally, it is recommended that social workers, counselors, and other professionals working with bereaved children and adolescents familiarize themselves with and educate themselves about trauma-informed care. Bereaved 
children and adolescents deserve the guidance of well-informed professionals.

\section{References}

American Psychological Association [APA]. (2013). Diagnostic and statistical manual for mental disorders (DSM 5). Arlington, VA: Author.

Arpawong, T. A., Oland, A., Milam, J. E., Ruccione, K., \& Meeske, K. A. (2013). Posttraumatic growth among an ethnically diverse sample of adolescent and young adult cancer survivors. Psycho-Oncology, 22(10), 2235-2244. doi: https://doi.org/10.1002/pon.3286

Brewer, J., \& Sparkes, A. C. (2011). Parentally bereaved children and posttraumatic growth: Insights from an ethnographic study of a UK childhood bereavement service. Mortality, 16(3), 204-222.

Brown, A. C., Sandler, I., Tein, J., Liu, X., \& Haine, R. (2007). Implications of parental suicide and violent death for promotion of resilience of parentally-bereaved children. Death Studies, 31(4), 301-335. doi: https://doi.org/10.1080/07481180601187092

Calhoun, L. G., \& Tedeschi, R. G. (2006). The foundations of posttraumatic growth: An expanded framework. In L. G. Calhoun \& R. G. Tedeschi (Eds.), Handbook of posttraumatic growth: Research and practice (pp. 3-23). Mahwah, NJ: Erlbaum.

Campbell, D., \& Stanley, J. (1963). Experimental and quasi-experimental designs for research. Chicago: Rand McNally.

Chaplin, T. M., \& Aldao, A. (2013). Gender differences in emotion expression in children: A meta-analytic review. Psychological Bulletin, 139(4), 735-765. doi: https://doi.org/10.1037/a0030737

Cohen, J. A., \& Mannarino, A. P. (2004). Treatment of childhood traumatic grief. Journal of Clinical Child and Adolescent Psychology, 33(4), 819-831. doi: https://doi.org/10.1207/s15374424jecp3304 17

Cohen, J., Mannarino, A. P., Greenberg, T., Padlo, S., \& Shipley, C. (2002). Childhood traumatic grief: Concepts and controversies. Trauma, Violence \& Abuse, 3(4), 307327. doi: https://doi.org/10.1177/1524838002237332

Cryder, C., Kilmer, R., Tedeschi, R., \& Calhoun, L. (2006). An exploratory study of posttraumatic growth in children following a natural disaster. American Journal of Orthopsychiatry, 76(1), 65-69. doi: https://doi.org/10.1037/0002-9432.76.1.65

Currier, J. M., Holland, J. M., \& Neimeyer, R. A. (2006). Sense-making, grief and the experience of violent loss: Toward a meditational model. Death Studies, 30, 403-428. doi: https://doi.org/10.1080/07481180600614351

Devine, K., Reed-Knight, B., Loiselle, K., Fenton, N., \& Blount, R. (2010). Posttraumatic growth in young adults who experienced serious childhood illness: A mixed-methods approach. Journal of Clinical Psychology in Medical Settings, 17(4), 340-348. doi: https://doi.org/10.1007/s10880-010-9210-7 
Dopp, A. R., \& Cain, A. C. (2012). The role of peer relationships in parental bereavement during childhood and adolescence. Death Studies, 36(1), 41-60. doi: https://doi.org/10.1080/07481187.2011.573175

Ellis, J., Dowrick, C., \& Lloyd-Williams, M. (2013). The long-term impact of early parental death: Lessons from a narrative study. Journal of The Royal Society of Medicine, 106(2), 57-67. doi: https://doi.org/10.1177/0141076812472623

Friedman, R. A. (2012). Grief, depression, and the DSM-5. The New England Journal of Medicine, 366, 1855-1857. doi: https://doi.org/10.1056/NEJMp1201794

Glad, K. A., Jensen, T. K., Holt, T., \& Ormhaug, S. M. (2013). Exploring self-perceived growth in a clinical sample of severely traumatized youth. Child Abuse \& Neglect, 37, 331-342. doi: https://doi.org/10.1016/j.chiabu.2013.02.007

Hafstad, G. S., Kilmer, R. P., \& Gil-Rivas, V. (2011). Posttraumatic growth among Norwegian children and adolescents exposed to the 2004 tsunami. Psychological Trauma: Theory, Research, Practice, and Policy, 3(2), 130-138. doi: https://doi.org/10.1037/a0023236

Hobfoll, S. E., Hall, B. J., Canetti-Nisim, D., Galea, S., Johnson, R. J., \& Palmieri, P. A. (2007). Refining our understanding of traumatic growth in the face of terrorism: Moving from meaning cognitions to doing what is meaningful. Applied Psychology: An International Review, 56(3), 345-366. doi: https://doi.org/10.1111/j.14640597.2007.00292.x

Hooper, L., Marotta, S., \& Lanthier, R. (2008). Predictors of growth and distress following childhood parentification: A retrospective exploratory study. Journal of Child \& Family Studies, 17(5), 693-705. doi: https://doi.org/10.1007/s10826-0079184-8

Horowitz, M. (2010). Grieving as well as possible: An insightful guide to encourage grief's flow, navigate difficult moments, and put your life or a friend's life back together. Sausalito, CA: GreyHawk Publishing.

Jia, X., Ying, L., Zhou, X., Wu, X., \& Lin, C. (2015). The effects of extraversion, social support on the posttraumatic stress disorder and posttraumatic growth of adolescent survivors of the Wenchuan Earthquake. Plos ONE, 10(3), 1-13. doi: https://doi.org/10.1371/journal.pone.0121480

Kaplow, J. B., Howell, K. H., \& Layne, C. M. (2014). Do circumstances of death matter? Identifying socioenvironmental risks for grief-related psychopathology in bereaved youth. Journal of Traumatic Stress, 27, 42-49. doi: https://doi.org/10.1002/jts.21877

Kilmer, R. P. (2006). Resilience and posttraumatic growth in children. In L. G. Calhoun \& R. G. Tedeschi (Eds.), Handbook of posttraumatic growth: Research and practice (pp. 264-288). Mahwah, NJ: Lawrence Erlbaum Associates, Publishers.

Kilmer, R. P., \& Gil-Rivas, V. (2010). Exploring posttraumatic growth in children impacted by Hurricane Katrina: Correlates of the phenomenon and developmental 
considerations. Child Development, 81(4), 1211-1227. doi:

https://doi.org/10.1111/j.1467-8624.2010.01463.x

Kilmer, R. P., Gil-Rivas, V., Griese, B., Hardy, S. J., Hafstad, G. S., \& Alisic, E. (2014). Posttraumatic growth in children and youth: Clinical implications of an emerging research literature. American Journal of Orthopsychiatry, 84(5), 506-518. doi: https://doi.org/10.1037/ort0000016

Kilmer, R. P., Gil-Rivas, V., Tedeschi, R. G., Cann, A., Calhoun, L. G., Buchanan, T., \& Taku, K. (2009). Use of the revised posttraumatic growth inventory for children. Journal of Traumatic Stress, 22(3), 248-253. doi: https://doi.org/10.1002/jts.20410

Kirwin, K. M., \& Hamrin, V. (2005), Decreasing the risk of complicated bereavement and future psychiatric disorders in children. Journal of Child and Adolescent Psychiatric Nursing, 18, 62-78. doi: https://doi.org/10.1111/j.1744$\underline{6171.2005 .00002 . x}$

Kissil, K., Nino, A., Jacobs, S., Davey, M., \& Tubbs, C. Y. (2010). 'It has been a good growing experience for me': Growth experiences among African American youth coping with parental cancer. Families, Systems \& Health, 28(3), 274-289. doi: https://doi.org/10.1037/a0020001

Laufer, A., \& Solomon, Z. (2006). Posttraumatic symptoms and posttraumatic growth among Israeli youth exposed to terror incidents. Journal of Social and Clinical Psychology, 25(4), 429-447. doi: https://doi.org/10.1521/jscp.2006.25.4.429

Laufer, A., Hamama-Raz, Y., Levine, S. Z., \& Solomon, Z. (2009). Posttraumatic growth in adolescence: The role of religiosity, distress, and forgiveness. Journal of Social and Clinical Psychology, 29, 860-862. doi: https://doi.org/10.1521/jscp.2009.28.7.862

Levine, S. Z., Laufer, A., Stein, E., Hamama-Raz, Y., \& Solomon, Z. (2009). Examining the relationship between resilience and posttraumatic growth. Journal of Traumatic Stress, 22(4), 282-286. doi: https://doi.org/10.1002/jts.20409

Li, J., Vestergaard, J., Cnattingius, S., Gissler, M., Bech, B. H., Obel, C., \& Olsen, J. (2014). Mortality after parental death in childhood: A nationwide cohort study from three Nordic countries. PLoS Medicine, 11(7), 1-13. doi: https://doi.org/10.1371/journal.pmed.1001679

Lin, X., Fang, X., Chi, P., Li, X., Chen, W., \& Heath, M. A. (2014). Grief-processingbased psychological intervention for children orphaned by AIDS in central China: A pilot study. School Psychology International, 35(6), 609-626. doi: https://doi.org/10.1177/0143034314535617

Linley, P. A., \& Joseph, S. (2004). Positive change following trauma and adversity: A review. Journal of Traumatic Stress, 17(1), 11-21. doi: https://doi.org/10.1023/B:JOTS.0000014671.27856.7e 
Little, S. G., Akin-Little, A., \& Somerville, M. P. (2011). Response to trauma in children: An examination of effective intervention and post-traumatic growth. School Psychology International, 32(5), 448-463. doi: https://doi.org/10.1177/0143034311402916

Malchiodi, C. A., Steele, W., \& Kuban, C. (2008). Resilience and posttraumatic growth in traumatized children. In C. Malchiodi (Ed.), Creative interventions with traumatized children (pp. 285-301). New York, NY: Guilford Press.

McCambridge, J., Witton, J., \& Elbourne, D. R. (2014). Systematic review of the Hawthorne effect: New concepts are needed to study research participation effects. Journal of Clinical Epidemiology, 67, 267-277. doi: https://doi.org/10.1016/j.jclinepi.2013.08.015

McClatchey, I. S., Vonk, M. E., \& Palardy, G. (2009). The prevalence of childhood traumatic grief: A comparison of violent/sudden and expected loss. Omega, 59(4), 305-323. doi: https://doi.org/10.2190/om.59.4.b

Meyerson, D. A., Grant, K. E., Carter, J. S., \& Kilmer, R. P. (2011). Posttraumatic growth among children and adolescents: A systematic review. Clinical Psychology Review, 31, 949-964. doi: https://doi.org/10.1016/j.cpr.2011.06.003

Nader, K. (2001). Guilt following traumatic events. Gift From Within-PTSD Resources for Survivors and Caregivers. Retrieved from http://www.giftfromwithin.org/html/Guilt-Following-Traumatic-Events.html

Oltjenbruns, K. (1991). Positive outcomes of adolescents' experience with grief. Journal of Adolescent Research, 6(1), 43-53.

Phipps, S., Long, A. M., \& Odgen, J. (2007). Benefit Finding Scale for Children: Preliminary findings from a childhood cancer population. Journal of Pediatric Psychology, 32, 1264-1271. doi: https://doi.org/10.1093/jpepsy/js1052

Pynoos, R. S., \& Steinberg, A. M. (2014). The UCLA PTSD Reaction Index for DSM-5, University of California, Los Angeles. Retrieved from http://www.nctsn.org/nctsn assets/pdfs/mediasite/ptsd-training.pdf

Pynoos, R. S., Steinberg, A. M., \& Wraith, R. (1995). A developmental model of childhood traumatic stress. In D. Cicchetti \& D. Cohen (Eds.), Developmental psychopathology: Risk disorder, and adaptation (Vol. 2, pp. 72-95). Oxford, U.K.: John Wiley.

Rogers, K. (2014). Placebo effect. In Encyclopadia Britannica online. Retrieved from http://eds.b.ebscohost.com.proxy.kennesaw.edu/

Substance Abuse and Mental Health Services Administration [SAMHSA]. (2015). Trauma-Informed Care and Alternatives to Seclusion and Restraint. Retrieved from http://www.samhsa.gov/nctic/trauma-interventions

Schafer, E. (2007). Training counselors role models. The basics and beyond. Camping Magazine, 80(3), 1-4. 
Steele, W., \& Kuban, C. (2011). Trauma-informed resilience and posttraumatic growth (PTG). Reclaiming Children \& Youth, 20(3), 44-46.

Steinberg, A. M., \& Brymer, M. J. (2008). The UCLA PTSD Reaction Index. In G. Reyes, J. Elhai, \& J. Ford (Eds.), Encyclopedia of psychological trauma (pp. 673674). Hoboken NJ: Wiley.

Sveen, J., Eilegard, A., Steineck, G., \& Kreicbergs, U. (2014). They still grieve: A nationwide follow-up of young adults 2-9 years after losing a sibling to cancer. Psycho-Oncology, 23(6), 658-664. doi: https://doi.org/10.1002/pon.3463

Tedeschi, R. G., \& Calhoun, L. G. (1995). Trauma and transformation: Growing in the aftermath of suffering. Thousand Oaks, CA: Sage. doi: https://doi.org/10.4135/9781483326931

Tedeschi, R. G., \& Calhoun, L. G. (1996). The posttraumatic growth inventory: Measuring the positive legacy of trauma. Journal of Traumatic Stress, 9(3), 455-471. doi: https://doi.org/10.1002/jts.2490090305

Tedeschi, R. G., \& Calhoun, L. G. (2004). Posttraumatic growth: Conceptual foundations and empirical evidence. Psychological Inquiry, 15, 1-18. doi: https://doi.org/10.1207/s15327965pli1501_01

Tedeschi, R. G., Calhoun, L. G., \& Cann, A. (2007). Evaluating resource gain: Understanding and misunderstanding posttraumatic growth. Applied Psychology: An International Review, 56(3), 396-406. doi: https://doi.org/10.1111/j.14640597.2007.00299.x

Trochim, W. M. K. (2006). The nonequivalent groups design. Research Methods Knowledge Base. Retrieved from www.soicalresearchmethods.net/kb/quasnegd.php

USAID. (2012). U.S. Government 5th Annual Report to Congress on Public Law 109-95: A United States Government Interagency Approach to Assisting the World's Most Vulnerable Children. Retrieved from https://www.usaid.gov/open/reports-congress

U.S. Social Security Administration. (n.d.). Social Security beneficiary statistics. Retrieved from https://www.ssa.gov/oact/STATS/SRVbenies.html

Wolchik, S. A., Coxe, S., Tein, J. Y., Sandler, I. W., \& Ayers, T. S. (2009). Six-year longitudinal predictors of posttraumatic growth in parentally bereaved adolescents and young adults. Omega: Journal of Death and Dying, 58(2), 107-128. doi: https://doi.org/10.2190/OM.58.2.b

Yu, X., Lau, J. T. F., Zhang, J., Mak, W. W. S., Choi, K. C., Lui, W.,...Chan, E. Y. Y. (2010).Posttraumatic growth and reduced suicidal ideation among adolescents at month 1 after the Sichuan earthquake. Journal of Affective Disorders, 123, 327-331. doi: https://doi.org/10.1016/j.jad.2009.09.019

Zebrack, B., Kwak, M., Salsman, J., Cousino, M., Meeske, K., Aguilar, C., \& ... Cole, S. (2015). The relationship between posttraumatic stress and posttraumatic growth 
among adolescent and young adult (AYA) cancer patients. Psycho-Oncology, 24(2), 162-168. doi: https://doi.org/10.1002/pon.3585

Zoellner, T., \& Maercker, A. (2006). Posttraumatic growth in clinical psychology: A critical review and introduction of a two component model. Clinical Psychology Review, 26(5), 626-653. doi: https://doi.org/10.1016/j.cpr.2006.01.008

Author note: Address correspondence to: Dr. Irene McClatchey, Program Director, Department of Social Work and Human Services, Kennesaw State University, 1000 Chastain Road, Kennesaw, GA 30144, 470-578-6630, imcclatc@ kennesaw.edu 